important subject of immunity and, at greater length, with the techniques for the in vitro culture of parasites.

This has been done with great skill but not without some loss of perspective, historical continuity having been sacrificed to modern developments. There is no mention in this book of Looss or Leiper, Thomas or Leuckart, or Dobell, Fuhrmann, Pintner, Railliet, Sinitsin, Skrjabin and a host of other dedicated pioneers whose classical researches illuminate the subject of parasitology and inspire the student to greater effort. There are sometimes lapses in matters which carry considerable weight of reliable opinion. In the account of ciliated Protozoa, for example, there is no mention of E. Fauré-Fremier and J. $\mathrm{O}$. Corliss, who created a new classification of the Ciliophora during the past decade, and the problem of coccidiosis is disenssed without mentioning the researches of E. E. Tyzzer and C. Horton-Smith. This criticism applies to groups other than the Protozoa; the author-index of the book is imposing but the chapter references often fail to indicate classical researches about which the student should know something.

The author's special fields of research are given the emphasis we would expect and they deserve, but the results of physiological researches with parasites are as yet so tenuous as to make unsatisfactory reading because areas of doubt and ignorance remain. There is some information about the chemistry and the mechanism of formation of egg-shell in the digenetic trematodes and the pseudophyllidean cestodes which requires revision, and the function of Mehlis's gland "remains obscure", while "how the operculum is formed remains a mystery". Statements about the blood-feeding habits of Fasciola, Clonorchis and Dicrocoelium are unsound and fail to harmonize with findings for Paragonimus, which has been studied in much greater detail. Another lapse is a failure to mention the in vivo technique using germ-free hosts, which, like in vitro culture methods, holds out great promise for the future. Axenically reared larvæ of Nippostrongylus muris, Nematospiroides dubius and Hymenolepis nana develop to normal fertile adults in germ-free guinea pigs, which are generally regarded as abnormal hosts for these parasites ${ }^{1}$. H. nana was more successful in the germfree host than in conventional hosts, which has interesting implications in the nutrition of this tapeworm. The use of germ-free hosts will also tend to improve the quality of our knowledge about hostspecificity.

What can or cannot be included in an introduction to parasitology is a moot point, and the present is catching up with the future now. Apropos of the axenic culture of Neoaplectana glaseri, the author states: "a number of media have been used to maintain $N$. glaseri, but these have been of biological origin and little attempt has been made to develop a defined culture medium". "This end has been achieved already ${ }^{2}$. A chemically defined medium containing eighteen amino-acids, a fatty acid, urea, Krebs cycle intermediates, purines, pyramidinos, B-group vitamins, glucose and also various inorganic constituents has fostered the development of third-stage larvæ of this nematode to the adult stage, with low but consistent level of reproduction. Incidentally, Jackson's aphorism should be memorized by all who enter this field of research: "cultures are as axenic as sterility tests are sonsitive; and the media as defined as glassware is clean and chemicals pure".
It should be remarkable if any book were published free of typographical errors, and this book is not remarkable in that respect. A few elegant pages are marred in this way but, apart from mentioning the erroneous spelling of the names Dollfus (pp. 236, 238, 437) and Heyneman (pp. 255, 438), I shall rest content to forward a list to the author. In spite of such blemishes and some other shortcomings, the author is to be complimented on the production of a progressive book which points the way to profitable future developments in the expanding scope of animal parasitology, a book which will do much to assist the progress of a generation of students so long as they do not neglect the finer details of morphology and taxonomy in their quest for physiological knowledge.

BEN DAWES

${ }^{1}$ Newton, W. L., Weinstein, P. P., and Jones, M. F., Ann. New York Acad. Sci., 78,290 (1959)

2 Jackson, G. J., Exp. Parasitol., 12, 25 (1962).

\section{A GUIDE TO ISOTOPES}

\section{The Radiochemical Manual}

Part 1: Physical Data. Pp. 102. (Amersham: The Radiochomical Centre, 1962.) $15 s$.

7 HIS handbook presents a great deal of accurate information about the availability and radiation characteristics of those radioactive isotopes, now numbering more than one hundred and fifty, which are in general use to-day. The bulk of tho information is contained in a table extending to some 60 pages which lists the isotopes in alphabetical order and gives for each the basic data of half-life, nature and strength of radiation, method of production, intensity available, and chemical form. Subsidiary tabulations summarize and slightly extend the data in special ways (for example, Table 6 lists beta-particle emitters in order of half-life). There are also graphs giving exposure data for the radiation from some isotopes commonly used in radiography.

It is inevitable in such an extensive compilation that there should be a number of slips, typographical and otherwise; these appear to be rather few and trivial. A more important criticism concerns the arrangement of the book as a whole. The order in which the six sections appear does not seem to be very logical; for example, Section 6 on the definition of terms might very well have been placed first and Section 1 on production of isotopes might very well have been combined with Section 3 on special irradiations in reactors. The intervening Section 2 on characteristics and availability of radioisotopes (pp. 3-84) is made rather top-heavy by Table 1 referred to above ("Physical Characteristics and Availability of Important Isotopes"); as one result of this, the explanation for the appearance of some of the isotopes tabulated in Tables 6 and 7 (pp. 78-81) in bold type is to be found on p. 3. Incidentally, the criteria for promotion of certain entries into bold type (importance of the radiation concerned) do not appear to have been consistently applied. The tables of sources of various kinds (Tables 10-14) deserve a place in the list of contents. These slight flaws in presentation of the data are redeemed, however, by a good index.

The Manual richly deserves a place by the side of the well-known Radiochemical Centre Catalogue on the desk of everyone concerned with the production and use of isotopes. The printing is excellent and the binding adequate.
K. F. Chackett 